\title{
Design and Analysis of Aluminum Alloy Wheel
}

\author{
Sriraj Undru ${ }^{1}$, Dr. P. Prabhakar Reddy ${ }^{2}$ \\ ${ }^{1}$ M.E CAD/CAM, CBIT, Hyderabad, Telangana. \\ ${ }^{2}$ PROFESSOR, MED CBIT, Hyderabad, Telangana.
}

\section{ABSTRACT}

Wheels are one of the most critical components in Automotive Engineering, As Fatigue prediction has been important issue in the design of aluminum alloy wheel. This work discuss the finite element techniques for simulation of functionality tests of aluminum alloy wheel and its Optimization of weight as well as stresses developed in the wheel. In this wheel is designed following the automobile standards for wheels and with required fatigue cycles, keeping in mind to reduce the mass of wheel optimally. To achieve this, different design iterations are modeled and analyzed to achieve a design with higher life cycles, strength and low mass. The modeling is made using unigraphics, and analysis is carried out in ansys work bench.

Keywords: Biaxial Fatigue Test, Cornering Fatigue Test, Impact Test, Modal Analysis, Radial Fatigue Test.

\section{INTRODUCTION}

Automotive wheels have evolved over the decades from early spoke designs of wood and steel, to flat steel discs and finally to the stamped metal configurations and modern cast and forged aluminum alloys rims of today's modern vehicles in aesthetic \& durability point of view. Historically, successful designs arrived after years of experience and extensive field testing. Since the 1970's several innovative methods of testing well aided with experimental stress measurements have been initiated. In recent years, the procedures have been improved by a variety of experimental and analytical methods for structural analysis (CAE). Within the past 10 years, durability analysis (fatigue life predication) and reliability methods for dealing with the variations inherent in engineering structure have been applied to the automotive wheel. Wheels are clearly safety related components and hence fatigue performance and the state of stress in the rim under various loading conditions are prime concerns. Wheels can be produced from steel \&Alloy of aluminum \& magnesium. Alloy wheels differ from normal steel wheels because of their lighter weight, which improves the efficiency of engine, easiness on steering operation \& speed of the car. However some alloy wheels are heavier than the equivalent size steel wheel due to their structure in line with the vehicle appearance. Alloy wheels are also better heat conductors than steel wheels, improving heat dissipation from the brakes, which reduces the chance of brake failure in more demanding driving conditions. Further, alloy wheels continue to receive a considerable amount of attention as a part of industrial efforts towards weight reduction through material substitution and down gauging. Although wheels are loaded in a complex manner and are highly stressed in the course of their rolling duty, light weight and road side styling is one of the prime requirements, hence cast and forged aluminum alloys are essential in the design.

Light aluminum alloy wheels enjoy a great popularity at present. For many consumers, a perceived exclusivity is a predominate factor, and these wheels are even considered as status symbols. The necessity to improve fuel consumption has caused many motor car manufacturers to break new ground in their vehicle design.

Knowing that an average design \& development period is 6 months or more depending on the requirements, iterations must be reduced at the physical prototype level and increased during virtual prototyping with a reliable methodology to predict the durability parameters, such as the fatigue life, impact tests as a part of rough road driving.

In the fatigue evaluation of a wheel design, the commonly accepted procedure for wheel manufacturers is to pass two durability tests, namely the radial fatigue test and the cornering fatigue test. The main objective in fatigue analysis is to predict the accumulated number of cycles at which crack initiates at a stress raising geometrical feature. The fatigue failure is related to the initiation and subsequent growth of these cracks under repeated loading and unloading. Apart from the above mentioned tests, an Impact test is also performed for analysis the rough road hit conditions.

The rim profile used for alloy wheels has to be in line with Tire \& rim association standards as tire \& rim will be assembled as a part of vehicle fitment. Styling \& loading requirements will vary from OEM to OEM.

The stress distribution in a wheel depends on the mode of operation and stress at any point in the wheel is composed of pre stress and service stress. The stress due to the manufacturing process, tire pressure and assembly to the hub are the pre stress on the wheel. The service stress are results of the wheel 
loads which are the vertical forces composed of static load due to the vehicle weight and dynamic forces developed passing road irregularities ,the lateral forces due to the quasis-static cornering forces as the most important ones. The longitudinal forces developed during braking and acceleration as well as the wheel aligning moments is considered to be secondary importance. High stress region in alloy wheel is spoke area (Styling surface).

\section{FUNCTIONALITY TEST OF WHEEL}

\section{A. Cornering Fatigue Test:}

The cornering fatigue test is one of the traditional durability tests of prototype verification. The aim of the test is to simulate the dynamic loading of the wheel during cornering on the road. The relevant forces acting on the wheel are a combination of the vertical load and lateral force developed between tire and ground. The two components of loading results in a rotating bending moment on the hub of the wheel. During the test, a constant or variable amplitude bending moment is applied to the wheel. In the rotary fatigue test, a wheel was mounted on a rotating table. A shaft was attached to the center of the wheel where a constant normal force was applied.

\section{B. Radial Fatigue Test:}

The Radial fatigue test is intended to find the structural performance of a wheel for normal highway use on passenger cars, light trucks and multipurpose vehicles. The wheel has to withstand repeated radial loading for a defined number of cycles in order to pass the test. The fatigue life of a wheel subjected to the repeated loading is calculated from the stress values obtained from static analysis. The accuracy of stress value depends on various parameters like tire modeling, simulation methods, load applications etc. The wheel with tire is going to fix to the machine equipment and it should be in contact to the rotating drum the drum is going to revolve by the motor by our required speed so here the important thing is we have to apply load on the tire for it we have to tie up a rope to the wheel and to the rotating drum sideward block so that the load required has to be set up by tightening the rope. In this way the motor has to be run for our required speed and we have to do this test continuously for two three hours and by taking short durations or long time we can do the experiment test by the way we have to note the cycles. At last after so many days we are going to get failure. By that we can estimate the life of the alloy wheel. In this way it is time taking test procedure, and we have to take correct procedure to follow up.

\section{Impact Test}

The wheel impact test is used to evaluate the impact performance, in which the striker is dropped from a specified height above the tire wheel assembly. It is considered to be the case where the wheel collides with the curb of the road or a large obstacle. The test is designed to evaluate the frontal impact resistance of wheel and tire assemblies used in all cars and multipurpose vehicles. The test is specifically related to vehicle pothole tests that are undertaken by most vehicle manufacturers. The scope has been expanded to allow the use of a striker that can be angled to preferentially impact the inboard and outboard wheel flange. Before the test, a wheel undergoes complete visual inspection to ensure that no cracks exist in the body.

\section{Bi Axial Test Of The Alloy Wheel:}

The traditional fatigue tests of wheel comprising the radial and cornering fatigue tests cannot simulate the real stress sate of wheel well because of the independent of these two tests, the real stress state of wheel cannot be well reproduced.

Biaxial wheel fatigue test evaluates the durability of the wheel under combine variable radial and lateral loads, which is demanded by many original equipment manufacturers especially in European market in recent years. Moreover, the complexity of tire wheel assembly cyclic loading distribution and wheel road conditions are considered synthetically in the test. Therefore the fatigue safety of the wheel can be tested and evaluated comprehensively by the biaxial wheel fatigue test.

\section{MATERIAL PROPERTIES}

\begin{tabular}{|l|l|l|l|}
\hline & $\begin{array}{l}\text { Aluminum } \\
\text { alloy }\end{array}$ & $\begin{array}{l}\text { Structural } \\
\text { steel }\end{array}$ & Polyethylene \\
\hline Density & $2770 \mathrm{kgm}^{-9}$ & $\begin{array}{l}7850 \\
\mathrm{kgm}^{-9}\end{array}$ & $950 \mathrm{kgm}^{-\mathbf{a}}$ \\
\hline $\begin{array}{l}\text { Young's } \\
\text { modulus }\end{array}$ & $7.1 \mathrm{x}^{10} 0^{10}$ & $2 \mathrm{x}^{10}$ & $1.1 \mathrm{x}^{11} 10^{9}$ \\
\hline $\begin{array}{l}\text { Poisson's } \\
\text { ratio }\end{array}$ & 0.33 & 0.3 & 0.42 \\
\hline
\end{tabular}

\section{STATIC ANALYSIS}

\section{A. Finite Element Analysis of Wheel for} Cornering Fatigue Test:

The 3D model of wheel with shaft was created in the UNIGRAPHICS, the modeling package and the same was exported to ANSYS, the finite element package using Parasolid translator

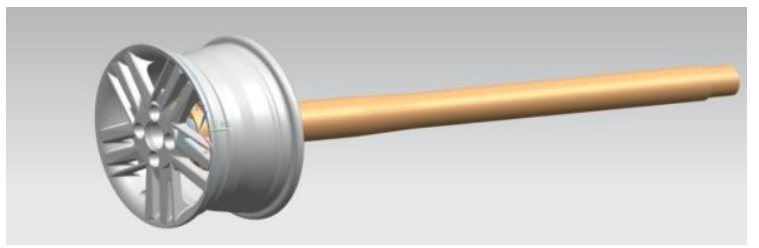

Fig 1: Solid model of wheel with shaft 
The wheel is meshed using tetrahedral element with mesh size of $0.2 \mathrm{~m}$.Here inner flange is constrained in all degree of freedom; vertical load of $1566.12 \mathrm{~N}$ is applied at the end of shaft in negative $\mathrm{Z}$ direction. Here the wheel is assigned with aluminum alloy, and shaft with structural steel. Same analysis repeated for 12 different position of the wheel to study where the maximum stress will occur.

\section{B. Finite Element Analysis of Wheel for Radial Fatigue Test:}

The 3D model of wheel with tire and slab assembly was created in the UNIGRAPHICS, the modeling package and the same was exported to ANSYS, the finite element package using PARASOLID translator.

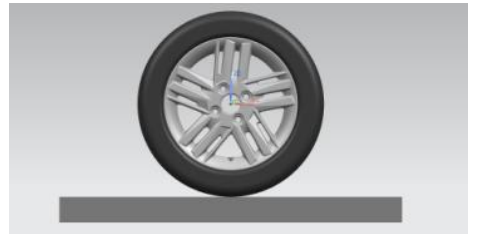

Fig 2: Solid model of wheel with shaft

The wheel is meshed using tetrahedral element. The number of elements was found to be 93052 and the number of nodes was found to be 178491.Here Lug holes and mounting flange surface are constrained in all degree of freedom. And the load of $9436 \mathrm{~N}$ is applied on the slab towards the wheel.

Here the wheel is assigned with aluminum alloy slab with structural steel \& tire with polyethylene. Same analysis repeated for 12 different position of the wheel to study where the maximum stress will occur.

\section{Finite Element Analysis of Wheel for $13^{\circ}$ Impact Test}

The 3D model of wheel with tire and slab assembly for 13 degree impact test was created in the UNIGRAPHICS, the modeling package and the same was exported to ANSYS, the finite element package using PARASOLID translator

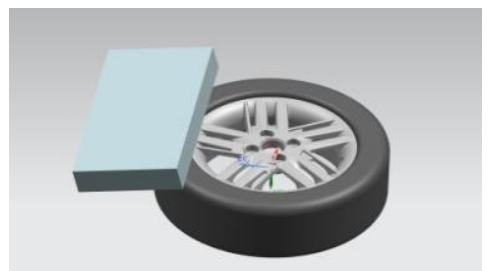

Fig 3: Solid model of wheel with tire and slab

The wheel is meshed using tetrahedral element. The number of elements was found to be 73607 and the number of nodes was found to be 132609.Here Lug holes and mounting flange surface are constrained in all degree of freedom and the load of $42007 \mathrm{~N}$ is applied on the slab in vertically downward direction. Here the wheel is assigned with aluminum alloy slab with structural steel \& tire with polyethylene. Same analysis repeated for 12 different position of the wheel to study where the maximum stress will occur.

\section{Finite Element Analysis Of Wheel For Bi-Axial Test:}

The 3D model of wheel with tire, shaft and slab assembly for bi-axial test was created in the UNIGRAPHICS, the modeling package and the same was exported to ANSYS, the finite element package using PARASOLID translator

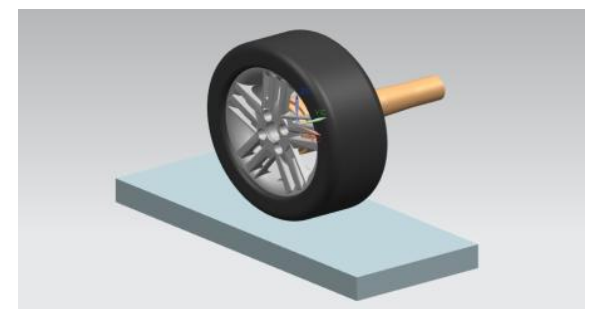

Fig4: Solid model of wheel with shaft and slab for biaxial test

The wheel is meshed using tetrahedral element of Element size $0.02 \mathrm{~m}$ Here Lug holes are constrained in all degree of freedom and the radial load of $42007 \mathrm{~N}$ is applied on the slab in vertically upward direction, side load of $3775 \mathrm{~N}$ is applied on the shaft. Here the wheel is assigned with aluminum alloy, tire with polyethylene and slab with structural steel. Same analysis repeated for 12 different position of the wheel to study where the maximum stress will occur.

\section{REDESIGN OF WHEEL}

To create the design domain for the alloy road wheel, in the existing wheel design. changes can be done only on the back side of the wheel, in front side of the wheel I cannot do any changes, front side of the wheel is non-design region. The design regions are areas in which material can be removed during the design synthesis. Non-design regions are areas where material cannot be removed, usually to keep important geometries intact, and thus the elements in these areas are excluded from the optimization process. We have done the following changes with topology optimization. Here mass is taken as the design variable for minimizing the volume. Here the inner side of spokes and hub area are considered as design area while the regions front side styling are taken to be non-design region. Four appropriate cases are considered to reach the objective. Cornering fatigue test, Radial fatigue test, modal analysis, Impact test. 


\section{MODAL ANALYSIS}

At present four wheeler wheels are made of Aluminum Alloys. In Design change proposal in order to reduce weight of wheel in this section, these proposals will be investigated for durability and NVH considerations. Reduction of vehicle noise and refinement of sound quality is becoming more important for occupant comfort. With the quick development of powertrain noise reduction, tire/road noise has become increasingly important referring to overall acoustic comfort. The tire/road noise dominates the interior noise of today's cars during middle constant speed with low load on coarse roads. Tire/road noise is divided into three frequency categories: low-frequency noise $(0-100 \mathrm{~Hz})$, midfrequency noise $(100-500 \mathrm{~Hz})$ and high-frequency noise (above $500 \mathrm{~Hz}$ ). Low frequency noise is easy to induce the passenger discomfort, such as nausea, vomiting during riding. With the increasing of people's living standard, the noise environment has also heightened, and the traffic noise regulations have been more and stricter year by year. In order to avoid undesired interior noise the natural frequency of the wheel should be higher than $350 \mathrm{~Hz}$ since this value is considered as critical frequency. Moreover, durability availability will be checked on defined condition in SAE J328. $5 \mathrm{~mm}$ metal removing has been applied by, to the areas that black colored and marked with in the oval shape.

The procedure for a modal analysis consists of four main steps:

1. Build the model.

2. Apply loads and obtain the solution.

3. Expand the modes.

4. Review the results.

\section{Degrees of freedom:}

The number of independent coordinates required to describe the motion of the system is defined as the degrees of freedom

Free conditions:

It's used to find the natural frequency and mode shape.

Table 1: Ansys setting used for modal analysis

\begin{tabular}{|l|l|}
\hline Object name & Modal \\
\hline State & solved \\
\hline Physics type & Structural \\
\hline Analysis type & Modal \\
\hline Solve target & Ansys mechanical \\
\hline Environmental temp & $22^{\circ}$ \\
\hline Generate input only & no \\
\hline Object Name & Object Name \\
\hline State & Fully Defined \\
\hline Pre-Stress Environment & None \\
\hline
\end{tabular}

\section{HARMONIC ANALYSIS}

A harmonic analysis is used to determine the response of the structure under a steady-state sinusoidal (harmonic) loading at a given frequency. A harmonic, or frequency-response, analysis considers loading at one frequency only. Loads may be out-ofphase with one another, but the excitation is at a known frequency. This procedure is not used for an arbitrary transient load.

To better understand a harmonic analysis, the general equation of motion is provided first:

$[\mathrm{M}]\{\bar{x}\}+[\mathrm{C}]\{\dot{x}\}+[\mathrm{K}]\{\mathrm{x}\}=\{\mathrm{F}\}$

In a harmonic analysis, the loading and response of the structure is assumed to be harmonic (cyclic).The harmonic analysis procedure is very similar to performing a linear static analysis, so not all steps will be covered in detail. The steps in yellow italics are specific to harmonic analyses.

- Attach Geometry

- Assign Material Properties

- Define Contact Regions (if applicable)

- Define Mesh Controls (optional)

- Include Loads and Supports

- Request Harmonic Tool Results

- Set Harmonic Analysis Options

- Solve the Model

- Review Results

Table 2: The analysis settings used for harmonic response are as follows

\begin{tabular}{|l|l|}
\hline Type & Directional acceleration \\
\hline Frequency range & Use parent \\
\hline Min frequency & $0 \mathrm{~Hz}$ \\
\hline Max frequency & $2048 \mathrm{~Hz}$ \\
\hline Display & Bode \\
\hline
\end{tabular}

Stiffness of a wheel can be calculated by

$\boldsymbol{k}_{\text {wheel }}=\left(2 \mathrm{x} \pi \mathrm{x} f_{2}\right)^{2}\left[M_{T}-M_{T}\left(f_{2}^{2} / f_{1}^{2}\right)\right]$

Where $f_{1}=$ Maximum frequency in harmonic response

$f_{2}=$ Min frequency in harmonic response

$\boldsymbol{M}_{T}=$ Mass of the wheel $=7.156 \mathrm{~kg}$

\section{Frequency Response:}

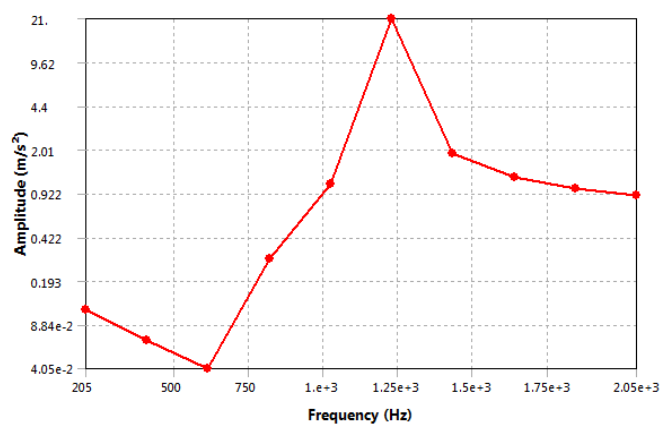

Fig 5: Harmonic response 
From the above harmonic response graph, $f_{1}=1228.8$ $\mathrm{Hz} f_{2}=616.4 \mathrm{~Hz}$

$\boldsymbol{k}_{\text {wheel }}=\left(2 \times 1 \pi x f_{2}\right)^{2}\left[M_{T}-M_{T}\left(f_{2}^{L} / f_{1}^{Z}\right)\right]$

\section{$\therefore k_{\text {wheel }}=82.47$}

VIII. RESULTS AND DICUSSION

A. Initial Finite Element Analysis Results For The Functionality Tests For The Model Wheel

All the functionality tests like cornering fatigue test, radial fatigue test and impact test were simulated in ANSYS, for 12 different position of the wheel, to find different plots of Von Mises stresses.

Based on the max stress value of the each test, further modification needs to be done for dropping of high stresses, here we have to make note that maximum stress value at air valve and at fixed position can be negligible for study because practically failure will not occur at this.

Table 3: Initial finite element analysis results

\begin{tabular}{|l|l|l|l|}
\hline AT ANGLE & $\begin{array}{l}\text { CFT } \\
(\mathrm{MPa})\end{array}$ & $\begin{array}{l}\text { RFT } \\
(\mathrm{MPa})\end{array}$ & $\begin{array}{l}\text { IMPACT } \\
(\mathrm{MPa})\end{array}$ \\
\hline $0^{\circ}$ & 118 & 61.5 & 803 \\
\hline $30^{\circ}$ & 105 & 42.1 & 790 \\
\hline $60^{\circ}$ & 119 & 57.8 & 752 \\
\hline $90^{\circ}$ & 116 & 55.3 & 873 \\
\hline $120^{\circ}$ & 117 & 56.9 & 850 \\
\hline $150^{\circ}$ & 114 & 66.4 & 873.1 \\
\hline $180^{\circ}$ & 118 & 56.3 & 890 \\
\hline $210^{\circ}$ & 103 & 59.7 & 791 \\
\hline $240^{\circ}$ & 119 & 50.28 & 897 \\
\hline $270^{\circ}$ & 112 & 64.4 & 789 \\
\hline $300^{\circ}$ & 117 & 62.3 & 87 \\
\hline $330^{\circ}$ & 115 & 51.8 & 811 \\
\hline & & & \\
\hline
\end{tabular}

Here from the results for $\mathrm{cft}$ max stress value is $119 \mathrm{Mpa}$,from component S-N curve(Fig 3.4) this stress value cannot with stand for 200000 cycles, for rft max stress is61.5MPa which may not with stand 600000 cycles, and to pass impact test the stress should below the $750 \mathrm{MPa}$. From above values it is not meeting the requirement for the wheel.so redesign has to be done, so that max stress for cft should be $90 \mathrm{MPa}$, for rft it should be $60 \mathrm{MPa}$ and for impact it should be $750 \mathrm{MPa}$.

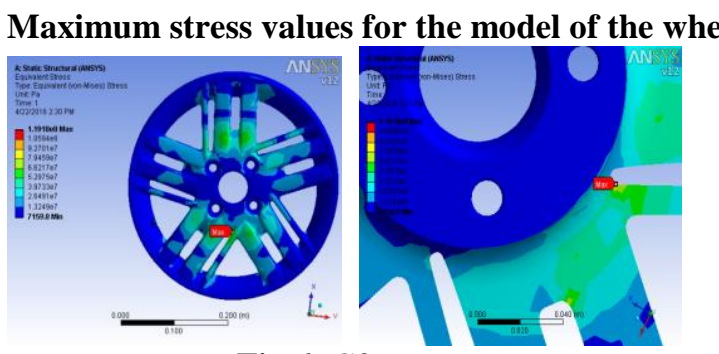

Fig 6: Cft max stress
From Fig 6 max stress for cft is $119 \mathrm{MPa}$ at edge of small spoke of the wheel. When the wheel is at $60^{\circ}$ rotated from the initial position.

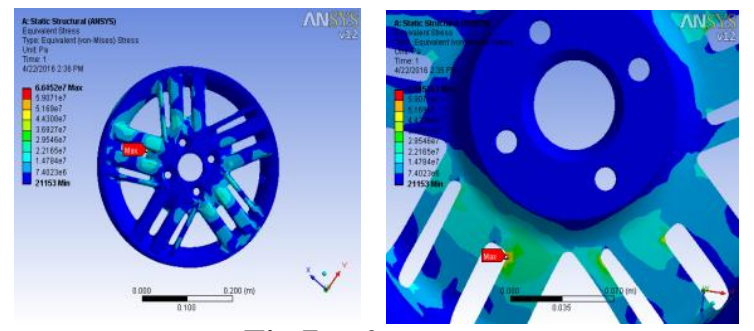

Fig 7: Rft max stress

Fig 7 is the max stress for rft at edge of the big spoke of wheel which is $66.4 \mathrm{MPa}$ at $180^{\circ}$ rotated from the initial position.
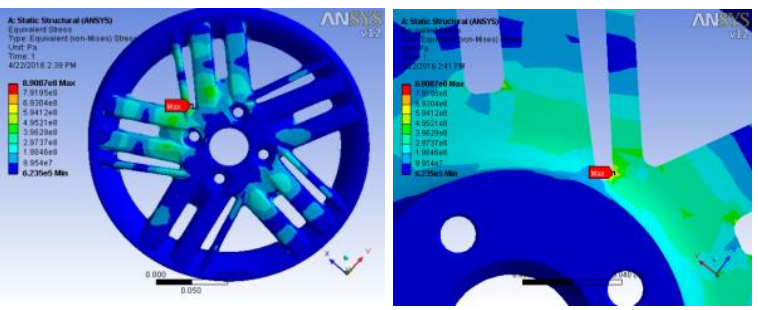

Fig 8: Impact max stress

From Fig 8 max stress for impact test is $873.1 \mathrm{MPa}$ at edge of small spoke of the wheel, when the wheel is at $150^{\circ}$ rotated from the initial position.

From the above results we came to know that small spoke of the wheel is weaker one, so modifications has to be done on that small spoke pocket length, The distance between the adjacent spokes has to be increase.

\section{B. Finite Element Analysis Results For The Functionality Tests Of Redesigned Wheel}

Table 4: Redesigned wheel finite element analysis results

\begin{tabular}{|l|l|l|l|}
\hline AT ANGLE & CFT $(\mathrm{MPa})$ & RFT $(\mathrm{MPa})$ & IMPACT $(\mathrm{MPa})$ \\
\hline $0^{\circ}$ & 82.8 & 55.10 & 714 \\
\hline $30^{\circ}$ & 82.1 & 45.1 & 720 \\
\hline $60^{\circ}$ & 84.5 & 57.3 & 700 \\
\hline $90^{\circ}$ & 84.5 & 52.8 & 716 \\
\hline $120^{\circ}$ & 85.2 & 53.5 & 673 \\
\hline $150^{\circ}$ & 86.9 & 58.8 & 708 \\
\hline $180^{\circ}$ & 82.7 & 44.5 & 706 \\
\hline $210^{\circ}$ & 82.9 & 55.73 & 711 \\
\hline $240^{\circ}$ & 86.3 & 51.0 & 738 \\
\hline $270^{\circ}$ & 84.5 & 57.1 & 675 \\
\hline $300^{\circ}$ & 85.1 & 57.6 & 658 \\
\hline $330^{\circ}$ & 86.8 & 49.9 & 710 \\
\hline
\end{tabular}

From the above results all the values are below the accepted stress values so this design will with stand or this design will meet the requirement of fatigue cycles. 
Maximum stress values for the redesigned model of the wheel

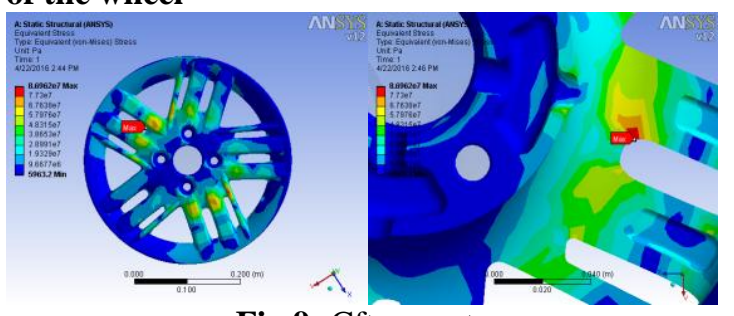

Fig 9: Cft max stress

From Fig 9 max stress for cft is $86.9 \mathrm{MPa}$ at edge of small spoke of the wheel, when the wheel is at $150^{\circ}$ rotated from the initial position.

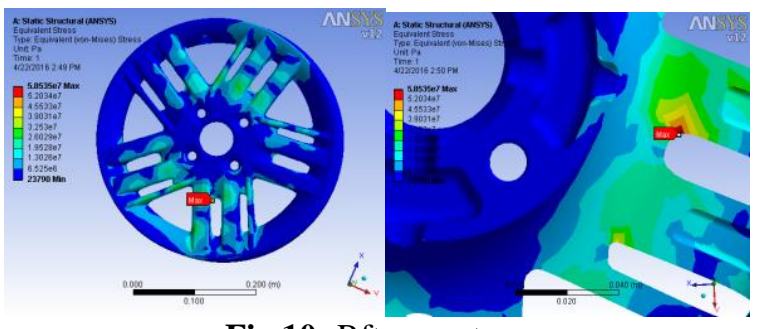

Fig 10: Rft max stress

Fig 10 is the max stress for $\mathrm{rft}$ at edge of the big spoke of wheel which is $58.8 \mathrm{MPa}$. at $150^{\circ}$ rotated from the initial position.
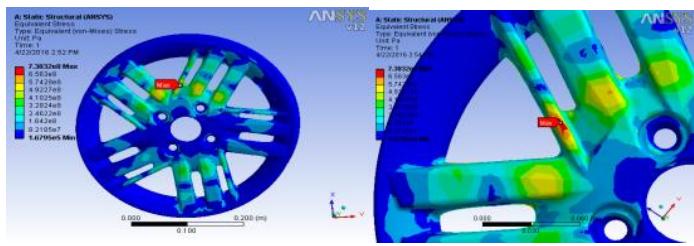

Fig 11: Impact max stress

From Fig 11 max stress for impact test is $738 \mathrm{MPa}$. at edge of small spoke of the wheel, when the wheel is at $240^{\circ}$ rotated from the initial position.

\section{Comparison Between Initial Wheel Design} Results To Redesigned Wheel Results

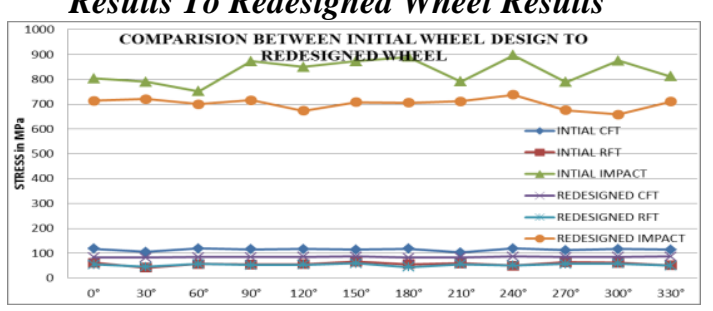

Fig 12: Graph between initial wheel results to redesigned wheel results

Fig 5.7 Illustrate the graph between stresses to different angle position of the wheel, in which variation of initial wheel design functionality test to redesigned wheel functionality tests as been shown, in which stress are reduced to great extent to achieve the required number of fatigue cycles.
D. Bi-axial test results for redesigned wheel

Table 5: Biaxial test results

\begin{tabular}{|l|l|}
\hline AT ANGLE & STRESS AT SPOKE AREA (Mpa) \\
\hline $0^{\circ}$ & 53.6 \\
\hline $30^{\circ}$ & 44.7 \\
\hline $60^{\circ}$ & 57.1 \\
\hline $90^{\circ}$ & 52.7 \\
\hline $120^{\circ}$ & 53.6 \\
\hline $150^{\circ}$ & 58.2 \\
\hline $180^{\circ}$ & 46.0 \\
\hline $210^{\circ}$ & 55.9 \\
\hline $240^{\circ}$ & 46.2 \\
\hline $270^{\circ}$ & 57.3 \\
\hline $300^{\circ}$ & 56.8 \\
\hline $330^{\circ}$ & 50.4 \\
\hline
\end{tabular}

These bi axial results are for redesigned wheel, from the above results all the values are below $60 \mathrm{MPa}$. Here in this work biaxial test simulation is done to study the stress distribution in the wheel.

\section{Bi-axial test maximum stress values}
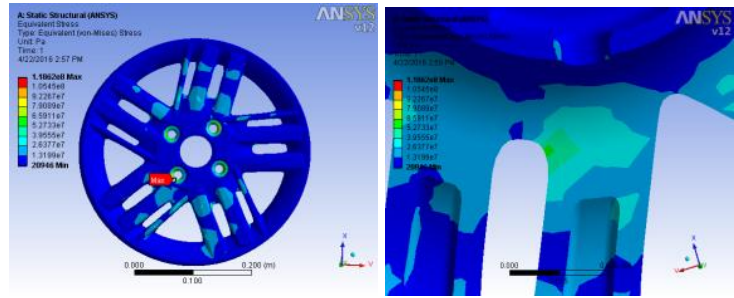

Fig 13: Bi-axial test max stress

From the fig 13 maximum stress value is at lug hole position, practically failure will not arise at the fixed position, so maximum value is taken at the spoke area. Here max stress value at spoke is $57.3 \mathrm{MPa}$.

\section{E. Modal analysis results}

Table 6: Natural frequency of the redesigned wheel

\begin{tabular}{|l|l|}
\hline Mode shape & Natural frequency(Hz) \\
\hline Mode 1 & 392.4 \\
\hline Mode 2 & 393.4 \\
\hline Mode 3 & 450.37 \\
\hline Mode 4 & 451.69 \\
\hline Mode 5 & 662.99 \\
\hline Mode 6 & 898.09 \\
\hline Mode 7 & 1063.8 \\
\hline Mode 8 & 1063.8 \\
\hline Mode 9 & 1638.6 \\
\hline Mode 10 & 1645 \\
\hline
\end{tabular}

Critical frequency for the redesigned wheel is 350 $\mathrm{Hz}$, here from the results at different speed all the natural frequency are above the critical.so there is no need for modifying the wheel.

\section{F. Manufacturing Feasibilty}

A manufacturing feasibility study aims to objectively and rationally uncover the strengths and weaknesses of developing product, opportunities and threats present in manufacturing, the resources required to carry through, and ultimately the 
prospects for success. Evaluation of the product's manufacturing capability can be done in this stage. Judging sequence of best suited manufacturing processes for the product to manufacture is the key to analyze this feasibility study.

Following are the manufacturing processes available for producing the cast wheel.

\section{Forging:}

Forging can be done by a one or multi-step process forging from various magnesium alloys, most commonly AZ80, ZK60 (MA14 in Russia).

Wheels produced by this method are usually of higher toughness and ductility than aluminum wheels, although the costs are much higher.

\section{High pressure die Casting (HPDC)}

This process uses a die arranged in a large machine that has high closing force to clamp the die closed. The molten magnesium is poured into a filler tube called a shot sleeve. A piston pushes the metal into the die with high speed and pressure, the magnesium solidifies and the die is opened and the wheel is released. Wheels produced by this method can offer reductions in price and improvements in corrosion resistance but they are less ductile and of lower strength due to the nature of HPDC.

\section{Low Pressure Die Casting (LPDC)}

This process usually employs a steel die; it is arranged above the crucible filled with molten magnesium. Most commonly the crucible is sealed against the die and pressurized air/cover gas mix is used to force the molten metal up a straw-like filler tube into the die. When processed using best practice methods LPDC wheels can offer improvements in ductility over HPDC magnesium wheels and any cast aluminum wheels, they remain less ductile than forged magnesium.

\section{Gravity Casting}

Gravity-cast magnesium wheels have been in production since the early 1920s and provide good ductility, and relative properties above what can be made with aluminum casting. Tooling costs for gravity-cast wheels are among the cheapest of any process. This has allowed small batch production, flexibility in design and short development time.

In current work, cast wheel is manufactured using low pressure die casting. Following are advantages for using low pressure die casting in manufacturing industries.

- Tooling cost is low compared to other manufacturing process

- Equipment cost is low

All products are not manufactural from every process. Based on the design of product its manufacturing process also differs accordingly. To feasibly manufacture cast wheel in LPDC some design considerations are taken into account.

- Chamfer and fillet should be more than $7 \mathrm{~mm}$

- Thickness of spoke should be more than $12 \mathrm{~mm}$

Chamfer and fillet are the secondary features which are performed after the basic operations in manufacturing any components. They play an important role in ejecting the casted component from the mold. Absence of fillet and chamfer leads to wear and damage at the edges of the product during ejecting. Based on the dimensions of the product and type of casting process the chamfer and fillet angles are provided. Caster wheel manufactured with chamfer and fillet less than $7 \mathrm{~mm}$ may lead to damage in the outer edges of wheel.

Technical feasibility study is performed based on the specifications of the requirement. Based on the technical analysis dimensions of the part are specified achieving their required specifications. Certain thumb rules are followed in manufacturing a product based on the technical feasibility or manufacturing feasibility. Thickness of spoke indicates strength of the wheel, which should withstand for the certain life span. For the same material property and profile, performance of wheel changes as the thickness of spoke varies. A minimum of $12 \mathrm{~mm}$ thickness is feasible for achieving the specifications for the caster wheel.

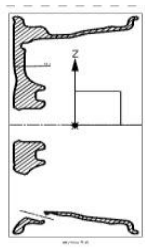

Fig 14: Cross section of wheel

In the present designed model, the spoke thickness is $14.1 \mathrm{~mm}$ which is feasible for both technically analysis and manufacturing standards.

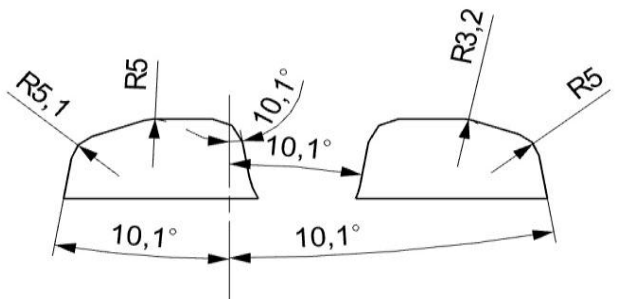

Fig 15: Various angels of cross section of spoke in $\mathrm{mm}$

Chamfer for the present designed model is $10.1 \mathrm{~mm}$, more than the required consideration for removing casted product from mold but fillet is $5.1 \mathrm{~mm}$ which results in minor wear and damages at the corners of the mold. 


\section{CONCLUSIONS AND FUTURE SCOPE OF THE WORK}

\section{E. Conclusions}

The following conclusions are drawn from the project work

1. Objective is to redesign alloy wheel based on the functionality test results like CFT and RFT, by satisfying this tests requirement optimization has been done.. The CAD model has been tested according to the cornering fatigue test, radial fatigue test, impact test and checked for biaxial fatigue test, natural frequency and stiffness in FEM simulation. Now we have achieved the best model with less weight and better strength and more durability, and it is feasible to manufacture.

2. Initial weight of the wheel is $7.35 \mathrm{Kg}$, and final weight obtained is $7.158 \mathrm{Kg}$, therefore percentage weight reduction is $2.72 \%$ achieved. Initial model maximum stress for cornering fatigue test is $119 \mathrm{MPa}$ and maximum stress for redesigned wheel cft is $86.9 \mathrm{mpa}$.Initial model maximum stress for radial fatigue test is $66.4 \mathrm{MPa}$ and maximum stress for redesigned wheel $\mathrm{rtt}$ is $58.8 \mathrm{MPa}$. Impact test initial maximum stress is 873.1 $\mathrm{MPa}$, maximum stress for redesigned wheel is $738 \mathrm{mpa}$. .Biaxial fatigue test maximum stress values for redesigned wheel are 57.3Mpa.

3. Natural frequency of the wheel should be more than $350 \mathrm{~Hz}$ to avoid NVH; present redesigned wheel has natural frequency more than $392.45 \mathrm{~Hz}$.

4. Stiffness of the present redesigned model wheel is $85 \mathrm{~N} / \mathrm{m}$ which is acceptable, stiffness of wheel should be $\min 45 \mathrm{~N} / \mathrm{m}$

5. With respect to the above results obtained, the initial model wheel fails in the entire functionality test and the redesigned wheel does not yield and gives the best values and is of good strength and better durable under the fatigue life of the metal. The Redesigned wheel is good acceptance with natural frequency and stiffness of the wheel.

\section{F. Future Scope Of The Work}

The scope of the project is:-

1. Design of the automotive alloy wheel using UNIGRAPHICS software, This product is generally used in automotive industry (14 inch alloy wheel, 15 spokes) for heavy load passenger car.

2. Simulation data and stress analysis data obtained can be used for developing the new design of alloy wheel.

3. All wheels are not made the same. The performance of an alloy wheel is a direct result of the manufacturing technique employed. In low pressure die casting positive pressure is used to move the molten aluminum into the mold quicker and achieve a finished product that has less mechanical properties. The cost involving the production of low-pressure casting is low. Flow forming is a specialized process begins with a low pressure type of casting and uses a special machine that spins the initial casting, heats the outer portion of the casting and then uses steel rollers pressed against the rim area to pull the rim to its final width and shape. To overcome cost and attain a light and strength part it's better to develop flow forming because during Flow Forming, pressure applied to the cast rim actually changes its mechanical properties, so its strength and impact values become similar to those of a forged rim. That translates to up to $15 \%$ less weight when compared to a standard cast wheel. In turn, less weight is key to record-breaking speed.

4. The earliest alloy wheels are made of magnesium. They found many problems in such as cracking, corrosion etc. Once these aluminum casting improvements were more widely adopted, the aluminum wheel took the place of magnesium as low cost, high-performance wheels for motorsports. They have a high price tag and easily prone to damage during collisions when compared to steel wheels. So a new alloy composition is to be developed which achieves the advantages of both steel and aluminum.

\section{REFERENCES}

[1] U. kocabicak et al. "Numerical analysis of wheel cornering fatigue tests". Engineering Failure Analysis. July, 2000.

[2] J. janardhan et al. "Radial fatigue analysis of an alloy wheel". Journal of engineering research and applications: Issn: 2248-9622, November, 2006.

[3] Santhshiishikawa, et al, "Application of impact analysis for aluminum wheel with inflated tire". Simulia community conference. May, 2014

[4] Muhmmetcerit et al, "Numerical simulation of dynamic side impact tests for an aluminum alloy wheel". Scientific research and essays: vol. 5(18), PP-2694-2701, 18, September, 2010.

[5] Sourav das et al, "Design and weight optimization of aluminum alloy wheel". International journal of scientific and research publications: Volume 4, issue 6, June, 2014

[6] Ch.P.V.Ravikumar et al, "Topology optimization of aluminum alloy wheel". International journal of modern engineering research: PP-1548-1553, June, 2013.

[7] Veh-lianghsu et al, "Developing an automated design modification system for 
aluminum disc wheels". Journal of engineering manufacture. Volume 221, No.3, March, 2007.

[8] B.G.N.satyaprasad, et al, "Topology optimization of alloy wheel" (2013).

[9] Liangmowang, et al, "Fatigue life analysis of aluminum wheels by simulation of rotary fatigue test". Journal of mechanical engineering 57(2011)1, 31-39, November, 2010.

[10] Samuel et al, "Comparison of loading functions in the modeling of automobile aluminum alloy wheel under static radial load". Journal of applied sciences: 5, 403413, .July, 2015.

[11] Xiaofeiwana et al, "Simulation of biaxial wheel test and fatigue life estimation considering the influence of tire and wheel camber", advances in engineering software:92 (2016) 57-64, October, 2015.

[12] S.sathe1r.et al "Analytical and experimental investigation of natural frequency by vibration of optimized alloy wheel". jetir (issn-2349-5162), November, 2015.

[13] Vivekanand et al, "To analyze the effect of fatigue load variation on wheel rim"., international journal of advanced engineering research and studies eissn2249-8974, September 2015.

[14] Tire and wheel rim association 2014.

[15] Draft Indian standard, performance requirements and method of test for wheel/rim for trucks, buses trailers, multi utility vehicles and multi-purpose passenger vehicles (first revision of is 9438). 